\title{
Extended Food Shelf-Life via Gamma Irradiation Modified Kraft Paper ${ }^{\dagger}$
}

\author{
Anamaria Irimia 1,* and Alin Enache ${ }^{2}$ \\ 1 Romanian Academy, "Petru Poni" Institute of Macromolecular Chemistry, Grigore Ghica Voda Alley, no. \\ 41A Iași, Romania \\ 2 Apel Laser SRL, Mogoșoaia, 25 Vanatorilor Street, Ilfov 077135, Romania; alin.enache@apellaser.ro \\ * Correspondence: anamaria.sdrobis@icmpp.ro; Tel.: +0332-880-220 \\ + Presented at the First International Conference on “Green” Polymer Materials 2020, 5-25 November 2020; \\ Available online: https://cgpm2020.sciforum.net/.
}

Published: 5 November 2020

\begin{abstract}
Cellulose, the main constituent of paper-based food packages, is a favorable substrate for fungal growth. Gamma irradiation is a well-established low-cost treatment used for decontamination of paper objects. The dose rate plays an important role in the efficacy of the radiation treatment, but further chemical treatment is also important for imparting specific properties for food packaging applications. The aim of this study is to evaluate the influence of $\gamma$ radiation dose and bioactive compounds grafting on appearance, structure and properties of two cellulosic substrates: unbleached and bleached Kraft cellulose paper. In this sense, Kraft paper has been activated using gamma irradiation treatment and grafted with two bioactive compounds, namely clove oil and rosehip seed oil. The experimental results showed that: (a) no significant changes of the irradiated samples took place, which prove a good durability; (b) the morphological and structural changes took place after modification with bioactive compounds, imprinting antimicrobial and antioxidant properties to modified substrates; (c) the modified materials extended the shelf-life of tested aliments, indicating that the new obtained materials are suitable for food packaging applications.
\end{abstract}

Keywords: Kraft paper; bioactive compounds; extended shelf-life

\section{Introduction}

The purpose of antimicrobial active packaging is to maintain the cleanliness and sterility of the product from the manufacturing plant through transport, shelf-life and storage, while maintaining their quality and sensorial properties [1]. In the last years, natural antimicrobial compounds (like vegetable oils) have been preferred over synthetic ones, in order to obtain more efficient antimicrobial materials [2].

Concerning the environment, petroleum-based polymers and aluminum layers are being replaced by polysaccharide-based materials, an eco-friendly technological solution. Compared to conventional plastic packaging materials, paper is preferred for food packaging application, due to its biocompatibility and easy-to-recycle nature [3,4].

The growth of microorganisms, which are already present in meat and meat products, cannot be interrupted through packaging only. To halt or reduce microbial growth, packaging has to be combined with other treatments, such as refrigeration, by heating/sterilization, or by using antimicrobial and antioxidant agents [5,6].

Surface modification of polymers by physical treatments based on plasma or gamma irradiation technologies are in many cases preferred, because apart from being environmentally friendly, in 
optima mild conditions, they selectively modify the topmost layers [7]. Also, the use of irradiation may overcome the main drawback associated with the conventional sterilization techniques that is the generation of liquid effluents.

This paper deals with ionizing radiation assisted modification of bleached and unbleached Kraft cellulose papers with two vegetable oils namely an essential oil (clove oil) and cold pressed obtained oil (rosehip seeds oil) in order to obtain new materials with antimicrobial and antioxidant activities for food packaging applications.

\section{Experiments}

\subsection{Materials}

The commercial unbleached (UKP) and bleached (BKP) Kraft cellulose paper was purchased from Adi Center SRL Iasi, Romania.

1-Ethyl-3-(3-dimethylaminopropyl) carbodiimide hydrochloride (EDC) and Nhydroxysuccinimide (NHS) used for the activation of hydroxyl groups were purchased from SigmaAldrich (Germany).

Clove Oil (purchased from FARES, Romania) and Rosehip Seeds Oil (purchased from S.C. Herbavit S.R.L, Romania), were chosen for paper modification, due to their high content of antioxidant compounds.

\subsection{Unbleached and Bleached Kraft Paper Functionalization}

The $\gamma$-irradiation process was performed in air at room temperature inside of a $\gamma$-irradiator $M$ 38 GAMMATOR (USA), which has a 137Cs source. The samples were spun continuously in front of split assuring a homogenous processing. The values of pre-irradiation $\gamma$-dose were 5, 10, 15 and 20 $\mathrm{kGy}$. After activation, the samples were immersed in the treatment chloroform solution (10 $\mathrm{wt} \%)$ of rosehip seed oil (RO) or methanol solution (10 wt\%) of clove oil (CO) for $60 \mathrm{~min}$, on mechanic stirring. For achieving the grafting, a mix of two chemical coupling agents was used: EDC and NHS. The samples were then extracted for $6 \mathrm{~h}$ in a Soxhlet extractor with chloroform or methanol, in order to remove the physically adsorbed chemicals, dried and analyzed.

\subsection{Investigation Methods}

The ATR-FTIR spectra have been recorded at $4 \mathrm{~cm}^{-1}$ resolution with 64 scans by means of a spectrometer Bruker VERTEX 70, in absorbance mode, by the ATR FTIR technique with a $45^{\circ} \mathrm{ZnSe}$ crystal. Background and sample spectra were obtained in the 600 to $4000 \mathrm{~cm}^{-1}$ wavenumber range.

\subsection{DPPH Radical Scavenging Assay}

The radical scavenging activity of Kraft cellulose paper was measured using the stable radical 2,2-diphenyl-1-picrylhydrazyl (DPPH). The radical scavenging activity was calculated according to the following equation:

$$
\% R S A=100 \times\left(1-\frac{A_{\text {sample }}}{A_{\text {control }}}\right)
$$

where: Asample represents the absorbance of the sample solution and Acontrol represents the absorbance of DPPH solution with the addition of the unmodified sample.

\subsection{Testing the Active-Food Packaging to Improve the Shelf-Life of Fresh Beef Meat}

Active film packaging were cut with the same dimensions and placed in sterile Petri dishes and sterilized with UV lamp for $24 \mathrm{~h}$. The experiment was carried out on beef meat originating from one local slaughter house delivered no later than $4 \mathrm{~h}$ after slaughter. Beef meat blocks were aseptically cut to $1 \mathrm{~cm}^{3}$ dimension using a specific slicer. The samples were distributed onto the active packaging 
films and the Petri dishes which were sealed and stored at $7{ }^{\circ} \mathrm{C}$. After 24 and $48 \mathrm{~h}$ of storage, the beef meat was determined for total viable counts at $30^{\circ} \mathrm{C}$ (ISO 4833:2003; Plate Count Agar at $30 \pm 1{ }^{\circ} \mathrm{C}$ for $72 \mathrm{~h}$ in aerobic conditions). The products are approved by the National Sanitary Veterinary and Food Safety Authority in Romania.

\section{Results}

\subsection{ATR-FTIR Spectra Results}

ATR-FTIR spectra were recorded to assess if any chemical or structural changes occurred upon gamma irradiation and further bioactive compounds modification of paper (Figure 1).

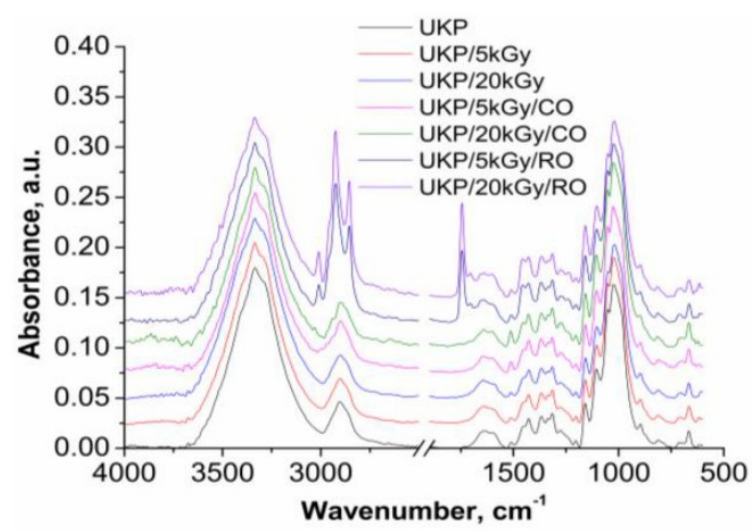

(a)

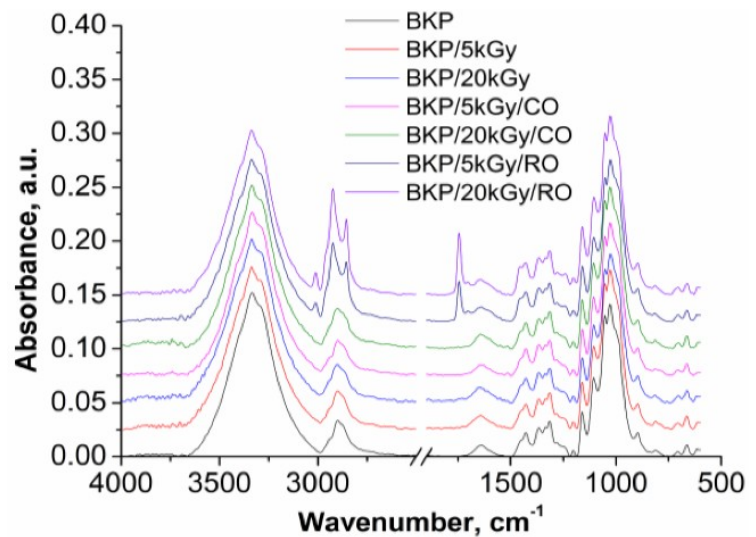

(b)

Figure 1. Normalized ATR-FTIR spectra of gamma irradiated sample (a) unbleached Kraft paper treated with clove oil and rosehip seeds oil and (b) bleached Kraft paper treated with clove oil and rosehip seeds oil.

Figure 1 presents the structural changes that appear in the FTIR spectra due to $\gamma$-irradiation and further vegetable oil modification: 3332, $3366 \mathrm{~cm}^{-1}$ (assigned to $\mathrm{OH}$ inter and intramolecular $\mathrm{H}-$ bond), 3032-3012, 2938-2924 $\mathrm{cm}^{-1}$ and a shoulder at $2851 \mathrm{~cm}^{-1}$ (assigned to $\mathrm{COOH}$ group, OH stretching vibrations), 1747, $1743 \mathrm{~cm}^{-1}$ (assigned to aromatic ring), $1642 \mathrm{~cm}^{-1}$ (assigned to $\mathrm{COOH}$ group, $\mathrm{C}=\mathrm{O}$ stretching vibrations), $1555,1515 \mathrm{~cm}^{-1}$ (assigned to $\mathrm{C}=\mathrm{O}$ asymmetric stretching vibration), $1456 \mathrm{~cm}^{-1}$ (assigned to -CH2- deformation vibrations), 1243, $1235 \mathrm{~cm}^{-1}$ (corresponding to -OC-O-COgroup, C-O stretching vibrations).

\subsection{DPPH Antioxidant Assay}

Table 1 presents the radical scavenging activity of both unbleached and bleached Kraft paper that was determined using the stable radical: 2,2-diphenyl-1-picrylhydrazyl.

Table 1. The values of unbleached and bleached Kraft paper concentration required to scavenge $50 \%$ of DPPH free radicals (IC50).

\begin{tabular}{cccc}
\hline Sample & IC50, $\mathbf{m g} / \mathbf{m L}$ & Sample & IC50, $\mathbf{m g} / \mathbf{m L}$ \\
\hline $\mathrm{UKP}$ & - & $\mathrm{BKP}$ & \\
$\mathrm{UKP} / 20 \mathrm{kGy} / \mathrm{CO}$ & 0.104 & $\mathrm{BKP} / 20 \mathrm{kGy} / \mathrm{CO}$ & 0.205 \\
$\mathrm{UKP} / 20 \mathrm{kGy} / \mathrm{RO}$ & 35.475 & $\mathrm{BKP} / 20 \mathrm{kGy} / \mathrm{RO}$ & 95.289 \\
\hline
\end{tabular}

IC50 is in the $\mathrm{mg} / \mathrm{mL}$ range and clove oil treated samples present a lower IC50 value than the ones treated with rosehip seeds oil for both unbleached and bleached Kraft paper, meaning that clove oil imprinted higher antioxidant activity. 


\subsection{Testing the $\gamma$-Irradiated Kraft Paper to Improve the Shelf-Life of Fresh Beef Meat}

The population dynamics of meat spoilage-related microorganisms (Total Number of Germs) tests are given in Figure 2.

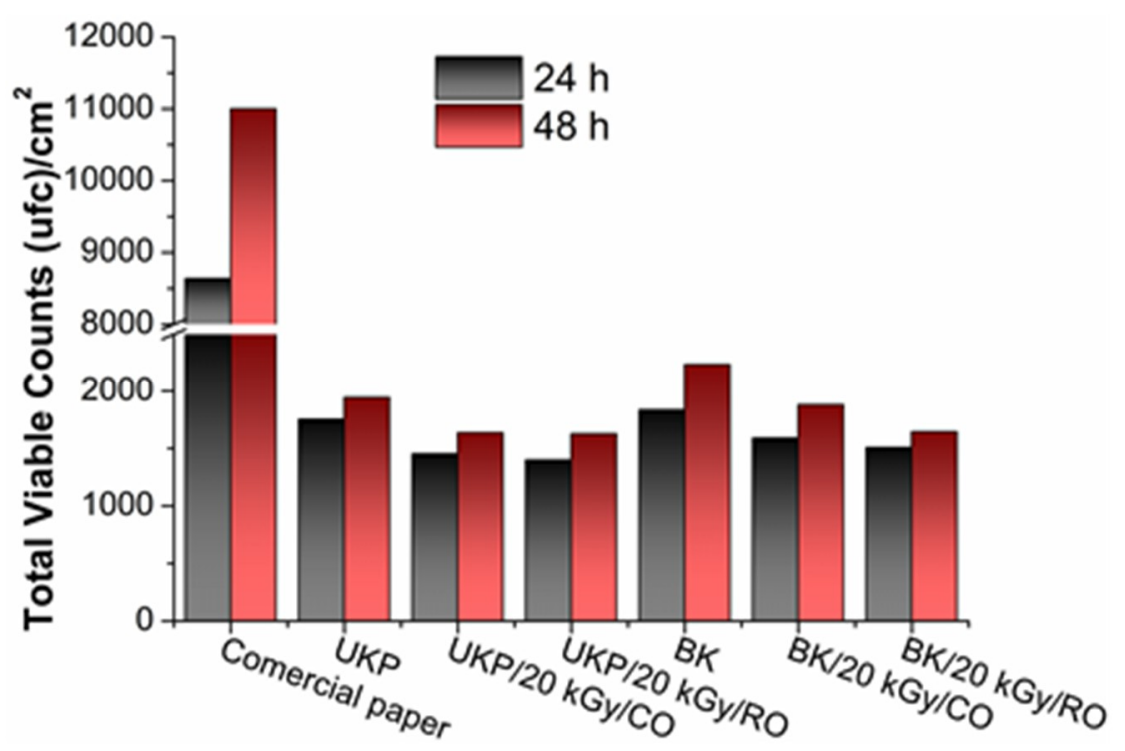

Figure 2. Total Viable Counts of untreated and $\gamma$-irradiated and vegetable oils modified paper for fresh beef meat

Although both clove oil and rosehip seeds oil proved to have antimicrobial activity and delay the spoilage of beef meat, rosehip seeds oil seems to be a more valuable antimicrobial agent in inducing antimicrobial activity than clove oil.

\section{Discussion}

Comparison between the FTIR spectra of non-irradiated and irradiated samples does not show evident variations in the relative intensities of the spectral features in the $4000-500 \mathrm{~cm}^{-1}$ range, in agreement with the observations of Coppola et al. [8]. Based on these results it can be concluded that the modification took place after activation by $\gamma$-irradiation and vegetable oils modification. However, it seems that the efficiency was higher for $20 \mathrm{kGy}$ dose of irradiation (Figure 1).

DPPH tests were conducted to evaluate whether the vegetable oils retained their antioxidant capacity after Kraft paper modification (Table 1). Hydroxyl groups present on their structure are believed to be associated with their antioxidant activity. The antioxidant activity depends on the effectiveness of the individual vegetable oil to modify the cellulose-based substrate in order to give a stable non-radical product. Considering that clove oil treated samples present a lower IC50 value than the ones treated with rosehip seeds oil for both unbleached and bleached Kraft paper, we can affirm that clove oil imprinted higher antioxidant activity.

Total Viable Counts (TVC) increased with the storage time (Figure 2). In commercial-packaged meat the TVC were significantly higher (between 8500 and 11,000 ufc/ $\mathrm{cm}^{2}$ ) than in UKP and BKP surfaces modified with vegetable oils (between 1400 and $1900 \mathrm{ufc} / \mathrm{cm}^{2}$ ). The modification of paper with active (antimicrobial and antioxidant) vegetable oils leads to a significant decrease of TVC when compared with the commercial paper or the untreated substrate. Both clove oil and rosehip seeds oil proved to be valuable antimicrobial agents for delaying the spoilage of beef meat; however rosehip oil seems to induce a better antimicrobial activity than clove oil. No changes were observed when comparing the $\mathrm{pH}$ of the samples with the initial $\mathrm{pH}$ of tested fresh beef meat. 


\section{Conclusions}

As a result of growth rate reduction and lag-phase extension, active films prevent the growth of pathogenic and spoilage microorganisms. Natural antimicrobial agents used in bioactive packaging prevent microorganism growth on foods surface, and can prolong the shelf life and safety of foods.

The present work shows that Kraft cellulose paper can be modify with some vegetable oils as clove oil and rosehip seeds oil, imparting good antioxidant and antimicrobial activity, which depend on type of oil used. Clove oil showed a higher antioxidant activity while rosehip seeds oil seems to be more efficient as antimicrobial agent. Structural and morphological properties of newly modified samples are influenced, changes confirmed by ATR-FTIR and SEM-EDX data. Antimicrobial activity of active packaging directly on food has been tested. The study indicates that these coatings can be used in food industry to prevent the contamination of surfaces by foodborne microorganisms.

Acknowledgments: The financial support of this work by European Social Fund for Regional Development, Competitiveness Operational Programme Axis 1-Project “Petru Poni Institute of Macromolecular Chemistry Interdisciplinary Pol for Smart Specialization through Research and Innovation and Technology Transfer in Bio(nano)polymeric Materials and (Eco)Technology", InoMatPol (ID P_36_570, Contract 142/10.10.2016, cod MySMIS: 107464) is gratefully acknowledged.

Conflicts of Interest: The authors declare no conflict of interest. The founding sponsors had no role in the design of the study; in the collection, analyses, or interpretation of data; in the writing of the manuscript, and in the decision to publish the results.

\section{Abbreviations}

The following abbreviations are used in this manuscript:

$\begin{array}{ll}\text { UKP } & \text { Unbleached Kraft Paper } \\ \text { BKP } & \text { Bleached Kraft Paper } \\ \text { EDC } & \text { 1-Ethyl-3-(3-dimethylaminopropyl) carbodiimide hydrochloride } \\ \text { NHS } & \text { N-hydroxysuccinimide } \\ \text { CO } & \text { Clove Oil } \\ \text { RO } & \text { Rosehip Seeds Oil } \\ \text { DPPH } & \text { 2,2-diphenyl-1-picrylhydrazyl } \\ \text { TVC } & \text { Total Viable Counts }\end{array}$

\section{References}

1. Coles, R. Introduction. In Food Packaging Technology; Coles, R., McDowell, D., Kirwan, M.J., Eds.; Blackwell Publishing, CRC Press: London, UK, 2003, pp. 1-31.

2. Becerril, R.; Nerín, C.; Silva, F. Encapsulation Systems for Antimicrobial Food Packaging Components: An Update. Molecules 2020, 25, 1134, doi:10.3390/molecules25051134.

3. Nešic, A.; Cabrera-Barjas, G.; Dimitrijevic-Brankovic, S.; Davidovic, S.; Radovanovic, N.; Delattre, C. Prospect of Polysaccharide-Based Materials as Advanced Food Packaging. Molecules 2020, 25, 135, doi:10.3390/molecules25010135.

4. Tayeb, A.H.; Tajvidi, M.; Bousfield, D. Paper-Based Oil Barrier Packaging using Lignin-Containing Cellulose Nanofibrils. Molecules 2020, 25, 1344, doi:10.3390/molecules25061344.

5. Marsh, K.; Bugusu, B. Food Packaging-Roles, Materials, and Environmental Issues. J. Food Sci. 2007, 72, R39-R55, doi:10.1111/j.1750-3841.2007.00301.x.

6. Vasile, C.; Darie, R.N.; Sdrobis, A.; Pâslaru, E.; Pricope, G.; Baklavaridis, A.; Munteanu, S.B.; Zuburtikudis, I. Effectiveness of chitosan as antimicrobial agent in LDPE/CS composite films as minced poultry meat packaging materials. Cell Chem. Technol. 2014, 48, 325-336.

7. Jordá-Vilaplana, A.; Fombuena, V.; García-García, D.; Samper, M.D.; Sánchez-Nácher, L. Surface modification of polylactic acid (PLA) by air atmospheric plasma treatment. Eur. Polym. J. 2014, 58, 23, doi:10.1016/j.eurpolymj.2014.06.002.

8. Coppola, F.; Fiorillo, F.; Modelli, A.; Montanari, M.; Vandini, M. Effects of $\gamma$-ray treatment on paper. Polym. Degrad. Stabil. 2018, 150, 25-30, doi:10.1016/j.polymdegradstab.2018.02.004. 
Publisher's Note: MDPI stays neutral with regard to jurisdictional claims in published maps and institutional affiliations.

(C) 2020 by the authors. Submitted for possible open access publication under the terms and conditions of the Creative Commons Attribution (CC BY) license (http://creativecommons.org/licenses/by/4.0/). 